\title{
Trajetória da Psicologia Organizacional e do Trabalho nos Simpósios da Associação Nacional de Pesquisa e Pós-graduação em Psicologia, antes de 2000
}

\author{
It's been a hard day's night \\ And I've been working like a dog \\ It's been a hard day's night \\ I should be sleeping like a log \\ (Lennon \& McCartney)
}

$\mathrm{O}$ presente número especial é um dos produtos do Grupo de Trabalho (GT), que funcionou em 2000 no âmbito do VIII Simpósio de Pesquisa e Intercâmbio Científico da Associação Nacional de Pesquisa e Pósgraduação em Psicologia (ANPEPP), denominado "GT: Desafios Metodológicos da Pesquisa em Psicologia Organizacional e do Trabalho". Este GT foi herdeiro de outros que funcionaram nos referidos Simpósios, em anos anteriores. Para uma melhor compreensão do que se passou, julgamos que deveríamos deixar aqui registrados o cenário que então percebíamos e nossa versão sobre a trajetória e fatos que levaram àquele evento.

\section{Cenário em que atuava o $G T$}

Dentre os diversos domínios de produção de conhecimento na Psicologia, no fim do século XX a Psicologia Organizacional e do Trabalho (POT) brasileira caracterizava-se (e obviamente continua a ser assim) como um dos menos desenvolvidos enquanto campo de pesquisa. Os seus pesquisadores, com projetos apoiados pelo Conselho Nacional de Desenvolvimento Científico e Tecnológico (CNPq), eram onze pessoas ou 7\% dos da Psicologia que recebiam esse apoio. Sete desses onze pesquisadores estavam no Distrito Federal, o que era um indicador da alta concentração dos esforços apoiados de pesquisa em muito poucas instituições. Além disso, somente três desses onze pesquisadores estavam classificados no nível 1 e um no nível 2A, o que sugeria que a maioria estava em início de carreira. As perspectivas de saída desse quadro, a curto prazo, eram remotas, considerando-se que esse domínio tinha no $\mathrm{CNPq}$, em relação à área da Psicologia, $3 \%$ das bolsas de mestrado e $2 \%$ das de doutorado no país e $6 \%$ das bolsas de doutorado no exterior. Em termos absolutos, essas bolsas eram uma dezena.

Havia poucos núcleos recentemente consolidados de pesquisa e um número de pesquisadores dispersos, muitos sem contar mesmo com o pequeno apoio do CNPq, em diferentes unidades da federação e cursos de pós-graduação e graduação, alguns fora da Psicologia (geralmente em Administração) e mesmo fora do ambiente universitário. As origens institucionais dos membros do GT que funcionou em 2000 provavelmente sugerem onde estavam esses pesquisadores: Universidades de Brasília (UnB) e Federais de Minas Gerais (UFMG), Santa Catarina (UFSC), Bahia (UFBA), Rio Grande do Norte (UFRN), Paraíba (UFPB), Fundação Getúlio Vargas de São Paulo (FGV-SP) e Universidade Metodista de São Paulo (UMESP), bem como outras instituições, que nos biênios anteriores tiveram participação em outros GTs (relacionados a POT), como as Universidades de São Paulo, em São Paulo (USP-SP) e em Ribeirão Preto (USP-RP), Federal de Uberlândia (UFU) e Estadual do Rio de Janeiro (UERJ), as Pontifícias Universidades Católicas de São Paulo (PUC-SP) e do Rio Grande do Sul (PUC-RS) e a Empresa Brasileira de Pesquisa Agropecuária (Embrapa). Outra instituição, com interesses de pesquisa em "organizações e trabalho", mas que somente participou do GT na condição de observadora, foi a UFRGS. Esses núcleos investigavam (e investigam) importantes questões relacionadas à compreensão do comportamento humano em contextos organizacionais e de trabalho, assim como práticas e políticas organizacionais e sociais relativas à gestão das pessoas que têm ocupações remuneradas. Criou-se, assim, um corpo inicial de conhecimento sobre o trabalhador, as organizações e as práticas de gestão no contexto nacional.

Constatou-se em 1994, como diagnosticou o GT relacionado a POT do V Simpósio da ANPEPP, a existência de um paradoxo. De um lado, era pequeno o seu peso relativo, em termos da formação inexpressiva que oferecia a grande maioria das instituições de ensino superior, da pouca presença de professores e pesquisadores qualificados a ela dedicados e da pouca importância (e até aviltamento) que a "Psicologia estabelecida" atribuía à POT. Este "lobo mau" da Psicologia, expressão cunhada por Wanderley Codo, ficou à margem do eixo principal desta ciência, nas instituições universitárias de ensino e pesquisa da Psicologia, onde esta vicejava. Por outro lado e por isso mesmo, não sofreu 
em todos os lugares e da mesma forma as conseqüências da crise por que passavam (e passam) estas instituições, crise esta que arrastava (e arrasta) os que elegeram essas instituições como locus privilegiado (ou único). A condição de desvalorização interna em que vivia (e vive) a subárea de "organizações e trabalho", nessas instituições, a forçou a buscar parcerias (por exemplo, em cursos de Administração e com empresas públicas e privadas), que lhe deram apoio estratégico e condições de desenvolvimento sustentado, além de a polinizarem e a forçarem a sair da endogenia. Como consequiência, a maior parte de sua produção nem é divulgada através dos meios típicos (congressos e revistas) da Psicologia nacional.

A realidade impõe múltiplos desafios, quando se tem em mente a necessidade de consolidação da POT, subárea que absorve um elevado contingente de profissionais da Psicologia, egressos dos seus cursos de graduação. Ao longo dos últimos doze anos, como demonstraremos mais adiante, a ANPEPP vem se constituindo em importante espaço para articulação desses pesquisadores em "organizações e trabalho”. Espaço não só de troca de experiência como também de constituição de projetos integrados de pesquisa, o que acabou culminando até com o apoio do Programa de Núcleos de Excelência (PRONEX) do Ministério da Ciência e Tecnologia, a alguns desses pesquisadores. Esse fato é extraordinário, dada a pequenez da pesquisa nacional em POT e considerando o fato de que somente dois núcleos da Psicologia brasileira até agora conseguiram tal reconhecimento desse Programa. Certamente é um indicador de que, embora o tamanho seja diminuto, já existe organização e amadurecimento suficientes para competir no cenário da ciência nacional e conseguir recursos escassos.

\section{Origens e história anterior ao GT 2000}

O primeiro GT relacionado a POT em Simpósios da ANPEPP, denominado "Estudos de Organização e Trabalho", ocorreu em 1990, durante o III Simpósio de Pesquisa e Intercâmbio Científico. Na época, estava composto por pesquisadores de pós-graduação da UnB, PUC-RS e PUC-SP. Discutiu sua estratégia de consolidação no âmbito dessa Associação, dado que o tema "organizações e trabalho" estava pouco desenvolvido nos cursos de mestrado e doutorado no país. Decidiu-se criar uma sistemática de comunicação entre os membros do GT e outros pesquisadores identificados, a fim de estimular o conhecimento mútuo da produção acadêmica brasileira e a ampliação do próprio Grupo. Os membros iniciais já se declaravam com uma postura metodológica e teórica aberta e pretendiam continuar nesta orientação no próximo Simpósio. Foram discutidos três trabalhos de pesquisa, cobrindo os temas: a dinâmica da subjetividade nos ambientes de trabalho, as representações sociais dos gerentes a respeito da gerência e a representação e regulação do sistema de produção. Dois deles tiveram seus resumos publicados nos Anais do evento.

No IV Simpósio, em 1992, quatro programas de pósgraduação foram representados no GT, bem como dois grupos de pesquisa, das seguintes instituições: UnB, PUC-SP, USP-SP, USP-RP, UFU e Embrapa. Nessa ocasião, o GT denominou-se "Ambiente, Funções e Comportamento Organizacional". Sua reunião permitiu uma avaliação das pesquisas na área de "organizações e trabalho", tendo sido encontrada uma identidade nos projetos desenvolvidos, necessitando contudo de maior sistematização para a efetiva consolidação do Grupo. A área necessitava se estruturar nos programas de pós-graduação, não havendo grupos de pesquisadores em número suficiente para sustentar uma linha de pesquisa nesses programas. Existiam pesquisadores isolados, nas diferentes instituições, tentando atender uma demanda cada vez maior.

O mercado de trabalho solicitava, de forma clara, profissionais com conhecimentos de questões mais aprofundadas do que aquelas tratadas tradicionalmente pelos cursos destinados à formação de recursos humanos. A emergência de novos programas de pós-graduação, que incluíssem nas suas áreas de concentração as temáticas de "organizações e trabalho" permitiria, por um lado, maior rigor científico no trato das questões colocadas pela demanda então existente e, por outro lado, criaria massa crítica de demanda para formação de docentes na área.

Os estudos e pesquisas apresentados e discutidos durante o encontro do GT focalizaram, de forma complementar, aspectos do trabalho e do fenômeno organizacional: uma proposta de classificação da pesquisa em psicologia organizacional, um estudo sobre as representações sociais dos acidentes de trabalho, uma pesquisa sobre processos atribuicionais em acidentes de trabalho, uma avaliação sobre mal estar do trabalho vazio em banco estatal, uma análise ergonômica da organização do trabalho em refinaria e um estudo sobre as consequiências da tarefa de digitação para leitura de textos. Os resumos de quatro desses seis trabalhos foram apresentados nos Anais do IV Simpósio e seus textos integrais foram publicados isoladamente pelos seus autores, em forma de artigos ou capítulos de livros.

Em 1994, no V Simpósio da ANPEPP, o Grupo de Trabalho (GT) "Uma Agenda de Pesquisa para a Psicologia Organizacional e do Trabalho" realizou uma análise e discussão das pesquisas brasileiras publicadas nos anos 1980-1993, em oito domínios da Psicologia Organizacional e do Trabalho (sob as disciplinas Psicologia, Administração, Educação, Sociologia e/ou correlatas): treinamento e desenvolvimento de pessoal, vínculos indivíduo - organização, formação e atuação do psicólogo organizacional, qualidade de vida no trabalho, avaliação de desempenho, atitudes e crenças 
relativas ao trabalho, saúde mental e trabalho e avaliação organizacional. Estiveram presentes pesquisadores da UnB, UFBA, UFSC, UFMG, UFU, Embrapa, e USP-RP. Em menos da metade desses casos, estes pesquisadores eram de programas de pós-graduação em Psicologia, sendo que nos outros casos eram de cursos de graduação em Psicologia, pós-graduação em Administração e de grupos de pesquisa isolados.

Foi feita uma revisão e uma organização sistemáticas do que tinha sido produzido, visando uma avaliação da medida em que a produção existente se inseria nas tendências mais recentes - quer temáticas, quer metodológicas - observadas na literatura internacional e realmente necessárias para o desenvolvimento social brasileiro. Tal avaliação permitiu começar a identificação de uma agenda de pesquisa para a área, que iria auxiliar na articulação das ações dos pesquisadores e dos estudantes de pós-graduação.

Para aquele Simpósio, cada participante do GT levou um trabalho, escrito individualmente ou em co-autoria, que sistematizou o estado da arte e apontou diretrizes para o desenvolvimento de estudos futuros, num dos oito domínios. Durante o V Simpósio, os trabalhos foram apresentados oralmente para o Grupo. Além disto, cada texto foi anteriormente lido por um dos membros do Grupo, que funcionou como debatedor principal e avaliador do que havia sido realizado, fazendo críticas e sugestões para melhoria, logo após a apresentação oral do trabalho. Finalmente, foi realizada uma discussão geral sobre os problemas da pesquisa em cada um dos domínios analisados, com base na apresentação do autor e na discussão iniciada pelo debatedor principal. Alguns desses textos foram publicados, de forma isolada, pelos seus autores.

O referido GT realizou, após as discussões das revisões apresentadas, um diagnóstico da pesquisa em Psicologia Organizacional e do Trabalho no Brasil e esboçou os seus próximos rumos. De acordo com esse diagnóstico, a pesquisa em POT sobreviveria em ambientes diferenciados, como a Psicologia, a Administração, a Educação e a Sociologia, sendo igualmente realizada fora e dentro das universidades, em alguns poucos programas de pós-graduação e fora deles. Haveria avanços significativos na natureza do conhecimento produzido. Ele seria interdisciplinar, gerado através de metodologias híbridas e altamente preocupado com sua institucionalização. Na área de "organizações e trabalho", a discussão sobre a relevância social da ciência psicológica estaria superada, principalmente no que concerne à questão da valoração apriorística dos problemas a serem pesquisados. Seria mais importante discutir como incorporar conhecimentos e tecnologias gerados nas cadeias de produção organizacional, nas ações dos trabalhadores e, principalmente, no ensino de graduação e pós-graduação em Psicologia.
À margem do eixo principal, teria surgido uma área de pesquisa preocupada em aproveitar as oportunidades de parcerias institucionais e em atender reivindicações de conhecimentos e tecnologias, contornando as barreiras existentes no sistema universitário brasileiro. Foram criadas alternativas de produção de conhecimento, retiradas do "modus operandi" de outras fontes que não a acadêmica. Com isso, contribuições já estariam disponíveis para as necessárias reformulações da relação ensino (de graduação e pós-graduação) - pesquisa nas instituições universitárias, faltando compartilhar e sistematizar as mesmas. Era nesta direção que o GT pretendia caminhar, no VI Simpósio, em 1996.

Por causa da existência de ameaças à sua sobrevivência e da exigência de um pensamento estratégico e de uma visão finalista, ainda de acordo com aquele diagnóstico, não teriam surgido em POT conflitos e disputas que resultassem em separações irreconciliáveis entre seus pesquisadores. Decidiu-se, no entanto, para fins de aprofundamento dos dois objetos essenciais de atenção da área (as organizações e o trabalho) e para melhor aproveitar as experiências de outros pesquisadores que tinham sido excluídos (por falta de espaço no GT), propor a criação de dois GTs para o VI Simpósio da ANPEPP. Um deles foi organizado pelo autor do presente texto, enquanto o outro foi paralelamente proposto pelo Prof. Wanderley Codo, existindo estreita articulação entre ambos os Grupos. Um terceiro GT, naquele momento mais interessado em questões de cultura, mudança e medidas em organizações brasileiras, foi proposto, de forma independente e paralela, pelo Prof. Álvaro Tamayo. Esses três coordenadores eram da UnB.

A avaliação final do GT, no V Simpósio, foi de que o produto da pesquisa em Psicologia Organizacional e do Trabalho era bom, mas necessitando de contar com um apoio mais generoso dos órgãos de fomento e das associações científicas e de respeito quanto à sua natureza híbrida e às formas de organização de sua produção e disseminação. De sua parte, os participantes discutiram e decidiram as estratégias para que isso pudesse ocorrer. A proposta feita para o Simpósio seguinte era uma dessas estratégias, tendo ela sido denominada "Relações entre Pós-graduação, Graduação e Pesquisa em Psicologia Organizacional”. Não por acaso, ela se articulava com os trabalhos realizados pelo GT anterior (no V Simpósio) e também com o tema geral do VI Simpósio da ANPEPP.

Em 1996, o objetivo a ser perseguido pelo então GT foi: "Através do relato, análise e discussão de experiências e propostas locais de integração entre graduação, pós-graduação e pesquisa em Psicologia Organizacional, sistematizálas em um conjunto que possa ser disseminado nacionalmente, a fim de sugerir alternativas e produzir avanços no ensino e pesquisa". Um objetivo muito similar, mas voltado 
para a pesquisa em Psicologia do Trabalho, foi definido pelo GT proposto pelo Prof. Wanderley Codo. O terceiro GT da área, no entanto, pretendia alcançar outros objetivos.

A proposta original incluía seis membros no GT de "Psicologia Organizacional” do VI Simpósio, mas um deles não pode comparecer nem enviou seu trabalho. Cinco textos, de pesquisadores da UnB, UFSC, UFPB e UFBA foram escritos, discutidos e revisados, cobrindo as seguintes temáticas: pesquisa qualitativa em psicologia e administração, aspectos psicossociais das cooperativas agrárias, comprometimento no trabalho, treinamento de pessoal e avaliação de desempenho ocupacional e estruturas de poder. Em três dessas instituições, já existiam programas de pós-graduação com áreas de concentração ou linhas de pesquisa em "organizações e trabalho". Os outros dois GTs, propostos paralelamente para o Simpósio, também discutiram trabalhos produzidos pelos seus membros. Decidiu-se publicar conjuntamente os textos discutidos, pelos pesquisadores dos três GTs, num volume especial dos Anais, patrocinado pela ANPEPP, e também na forma de um livro com edição comercial, aprovada pela ANPEPP, que seria uma estratégia para possibilitar mais ampla divulgação dos textos. O referido livro foi lançado em 1997 e em 2001 teve sua primeira edição esgotada.

No VII Simpósio, em 1998, continuaram a funcionar os três GTs já citados. O GT com o foco em "organizações e trabalho" foi denominado "Comportamento Organizacional: indivíduo, processos organizacionais e contextos de trabalho". Em sua proposta original foram incluídos sete membros, mas somente seis compareceram, vinculados às seguintes instituições: UnB, UFBA, UFPB, UFSC e UERJ (quatro delas com programas de pós-graduação em Psicologia, com áreas de concentração ou linhas de pesquisa enfocando "organizações e trabalho").

Os objetivos do Grupo de Trabalho, no referido ano, foram:

1. realizar intercâmbio de informações, referentes aos temas definidos, e sobre linhas de pesquisa em andamento nos Programas de Pós-graduação nacionais;

2. discutir pesquisas em processo de realização ou em fase imediatamente anterior à publicação dos seus resultados, de modo que o grupo ainda pudesse contribuir para a sua melhoria;

3. discutir estratégias implementadas de investigação dos temas definidos, de forma a contribuir para o aperfeiçoamento e melhor adequação entre objeto, problemas e metodologias de pesquisa;
4. organizar ou desenvolver parcerias entre programas de pós-graduação, para realizar trabalhos de pesquisa e ensino nos temas definidos;

5. debater e formular estratégias de incentivo e mobilização de pesquisadores - psicólogos para o campo de estudos das organizações brasileiras;

6. discutir políticas e prioridades de pesquisa e ensino de pós-graduação, nos temas definidos;

7. trocar informações sobre convênios e instituições de ensino e pesquisa no exterior, assim como sobre fontes alternativas de financiamento de pesquisas.

Os trabalhos de pesquisa apresentados e discutidos incluíram as seguintes temáticas: mudanças organizacionais e comprometimento no trabalho, avaliação de programas e sua influência comportamental no mundo agrário, impacto de treinamento no trabalho, comportamento humano e planejamento estratégico em organizações, poder e justiça nas organizações de trabalho e representações sociais do poder em organizações governamentais. Os cinco primeiros trabalhos tiveram seus textos revisados e foram submetidos para publicação em um número especial da revista "Psicologia e Sociedade", da Associação Brasileira de Psicologia Social (ABRAPSO). Essa revista publicou alguns deles, junto com outros que tinha recebido como resultado de uma chamada para um número especial, e a ABRAPSO sugeriu aos integrantes do GT que, considerando o estágio de produção científica na área, teria chegado o momento de investir esforços na criação de uma revista científica especializada em POT. A criação dessa revista, bem como sua estrutura, procedimentos e critérios, foram discutidas entre os membros do GT, bem como entre membros dos outros dois GTs "irmãos" que funcionaram no VI e VII Simpósios. Seu primeiro número começou a circular em 2001, com o nome de "Psicologia: Organizações e Trabalho", sendo o segundo autor do editorial do presente número escolhido como seu primeiro editor.

A continuação desta história, referente ao VIII Simpósio ocorrido em 2000, está contada naquele editorial.

\footnotetext{
Are you sad because you're on your own? No, I get by with a little help from my friends I get high with a little help from my friends I'm gonna try with a little help from my friends (Lennon \& McCartney)
}

Jairo E. Borges-Andrade (Universidade de Brasília) Editor convidado 